\title{
POST CRACKING BEHAVIOR OF LIGHTLY REINFORCED CONCRETE BEAMS
}

\author{
FREDE A. CHRISTENSEN ${ }^{*}$, JENS P. ULFKJ/ER*, RUNE BRINCKER ${ }^{\dagger}$ \\ Aarhus University \\ Aarhus, Denmark \\ e-mail: : fac@ase.au.dk jpu@eng.au.dk \\ ${ }^{\dagger}$ Technical University of Denmark \\ Copenhagen, Denmark \\ e-mail: runeb@dtu.dk
}

Key words: Reinforced Concrete Beams, Minimum Reinforcement Ratio, Size Effects.

\begin{abstract}
The main object of the research work presented in this paper is to establish design tools for lightly reinforced flexural concrete members subjected to bending load. An analytical model for predicting the load deflection curve is established and compared with experimental results. The main focus will be minimum reinforcement requirements and the related size effects. The main idea of the analytical model is to assume that the response of the structure can be described by the cracking response located within a fracture band. Outside the fracture band Bernoulli-Euler beam theory is assumed. The constitutive model for the concrete is based on the idea that the initial part of the stress crack width relation can be described by a linear relation between load and crack width, taking into account the stresses caused by aggregate interlocking. The model follows ideas previously used by other researchers in order to describe the fracture mechanics of concrete beams. These ideas are extended in this model to take into account the pullout of the reinforcement.
\end{abstract}

\section{INTRODUCTION}

The relationship between the applied load $P$ and the midspan deflection of a three-point bending beam shows a softening branch during crack growth, Figure 1. Although the crack appears in the ascending branch of the curve, its propagation is initially stable and the applied load continues to increase up to a peak. From this point, crack propagation becomes unstable in the sense that the applied load decreases with an increase in deflection. The maximum load attained at the peak, will in the following be denoted the first peak load. One traditional approach to minimum reinforcement is to require the yield load to be at least the value of the first peak load. After the introduction of the fictitious crack model [1] a lot of attention has been devouted on how this model can be applied to describe the fracture of concrete. The idea of a crack band model was first proposed by Bazant and $\mathrm{Oh}$ [2]. Bosco and Carpinteri [3] were the first to apply these ideas on an analytical model for the minimum requirements of concrete To model size effects in plain concrete beams Ulfkjær, Krenk and Bricker [4] developed a fracture band model. In this work

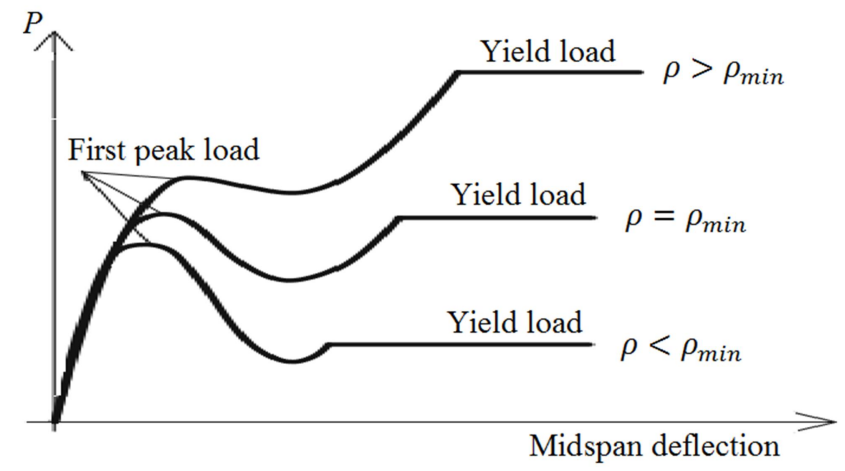

Figure 1: Traditional approach to minimum reinforcement requirements. 
the fracture band model assumed a linear softening relation. Planas, Guinea and Elices [5] used a model, based on the same ideas, with a linear softening relation in order to describe aspects concerning the modulus of rupture of plain concrete beams and used these considerations to investigate the minimum reinforcement requirements for reinforced concrete beams. In connection with a work on ligthly reinforced high strength concrete, Hededahl and Kroon [6] derived a fracture band model with main reinforcement. They used a linear softening relation for the concrete and assumed perfect bond between concrete and main reinforcement. The model presented here extend the previous work by taking into account pullout of the reinforcement. It should be noticed that a simmilar work has been performed by Olesen [7], however in this work another constitutive model has been adopted for the concrete and the developement of the zones with constant friction stresses is done in another way than in the work presented here. A collection of analytical and numerical approaches to size effects and minimum reinforcement requirements can be found in [8-17].

\section{MODEL DESCRIPTION}

In this section the analytical model is described. The main assumptions are divided into two sections; one dealing with assumptions concerning the stress-strain relation of the fracture band and one section dealing with the pullout of the main reinforcement.

\subsection{Characterization of the concrete}

Exposing a plain concrete specimen to uniaxial tension, linear proportionality between the load and the deformations are usually a valid assumption for small values of the load. At this stage the deformations are uniformly distributed along the specimen. Performing the tensile loading by monotonously increasing the deformation of the specimen, a peak load occurs when

the

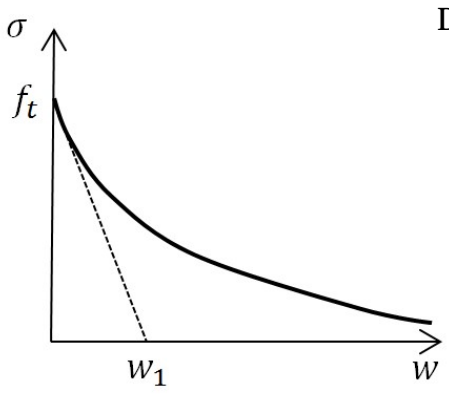

DOI 10.21012/FC9.128

Figure 2: Linear approximation of the stress crack width relation.

tensile strength is reached. After the peak load is reached, the deformations are localized due to formation of a crack. For this crack to open pullout of the aggregate from the cement paste will occur leading to a tensile stress $\sigma$ being transferred through the crack. Increasing the crack width leads to smaller values of the load transferred through the crack. It has previously been shown that this initial part of the stress crack width relation can be described by a linear relation, See e.g. [18-20]. In order to describe the initial part of the stress crack width relation, the tensile strength $f_{t}$ and the crack width $w_{1}$ is introduced, figure 2 . To be able to translate the stress crack width relation into a stress strain relation, a fracture band is introduced, figure 3. The fracture band is assumed to deform in such a way that the sections remain plane. Following this approach the crack opening $w$ is smeared through the thickness of the fracture band with length $h$. The deformations within the fracture band consist partly of the crack width and elastic deformations, figure 4 . Thus the strain within the fracture band is described by:

$$
\varepsilon=\frac{\sigma}{E_{c}}+\frac{w}{h}
$$

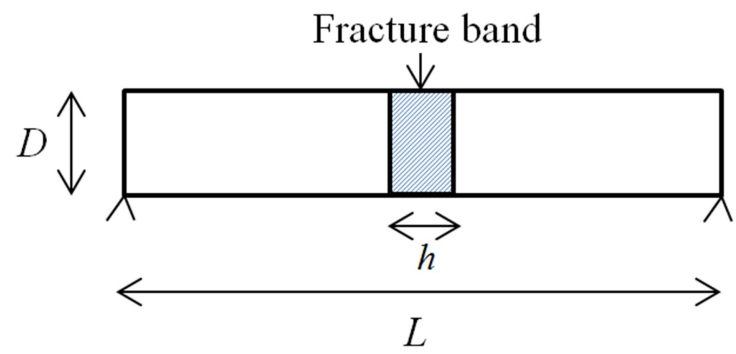

Figure 3: Beam with fracture band. 


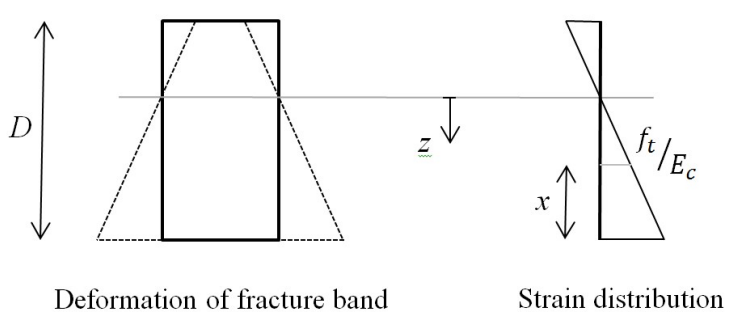

Figure 4: Kinematics of the fracture band.

Where $E_{c}$ is the modulus of elasticity of the concrete. The stress strain relation is divided into three parts; A first part with strain less than the critical value $f_{t} / E_{c}$. A second part, the softening branch of the stress strain relation, where the stress and strain may be related through the slope $E_{s o f t}$ which may be expressed as, figure 5:

$$
E_{\text {soft }}=k E_{c} \quad k=\frac{h}{l_{1}-h}
$$

where the characteristic length $l_{l}$ is defined by [5]:

$$
l_{1}=\frac{E_{c} w_{1}}{f_{t}}
$$

Increasing the length of the fracture band $h$ increases the value of $k$ and the absolute value of the softening modulus $E_{\text {sofft }}$. When $h \rightarrow l_{l}$ the slope of the softening part becomes vertical. Thus the model is only valid until a certain degree of brittleness of the structure (Elices, Guinea \& Planas 1994). For the third part of the stress strain relation, the stress is equal to 0 . The compression zone is assumed to remain linear elastic for all values of the load.

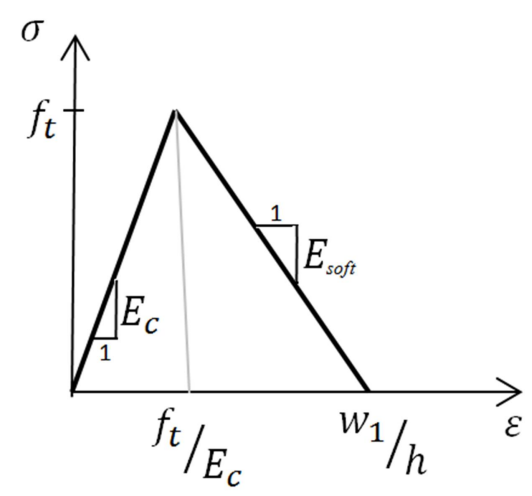

Figure 5: Stress strain relation for the crack band.

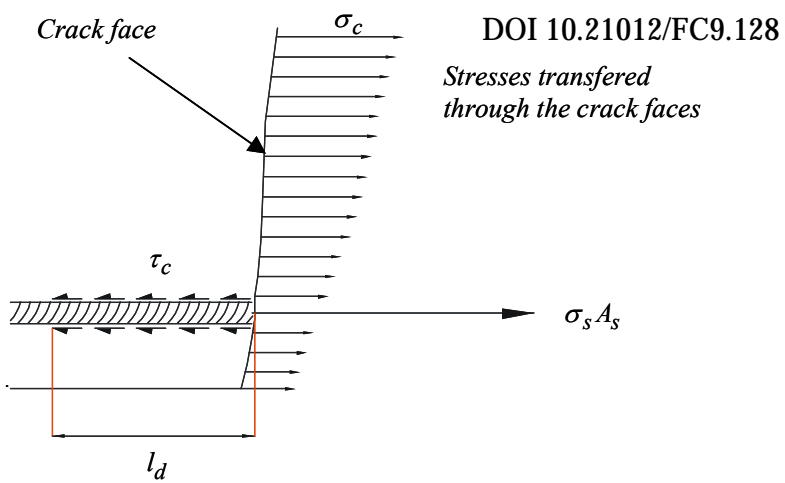

Figure 6: Considerations concerning pullout of the reinforcement.

\subsection{Pull-out of the reinforcement}

The significance of this study is concerned with how to include the main reinforcement. Before the crack crosses the main reinforcement, perfect bond between the steel and the concrete is assumed. In order for the crack to open, slip between the steel and the concrete has to take place. In this model this is taken into account by assuming development of zones around the crack with constant friction stresses $\tau_{c}$. Consider the situation around the reinforcement shown in figure 6 . The stress in the steel at the crack face is equal to $\sigma_{s}$. At the crack faces the stress $\sigma_{c}$ is acting. A zone of constant friction stresses equal to $\tau_{c}$ with the length $l_{d}$ is developed at each side of the crack. Now assuming that the stress at the end face of the debonded zone is equal to $\sigma_{c}$ the crack width $w_{s}$ is given by integrating the differences in strain between the steel and the concrete. This leads to the following equation for the crack width $w_{s}$ :

$$
\sigma_{s}=\sqrt{\frac{2 \tau_{c} E_{s}}{r_{d}} w_{s}}+\alpha \sigma_{c}
$$

where $E_{s}$ is the modulus of elasticity for the reinforcement, $r_{d}$ is the radius of the rebars and $\alpha$ is $E_{S} / E_{c}$.

\subsection{Model solution}

The model is established by introducing a number of phases depending on the length of the crack. The equations of the model are set up by analysis of these stress distributions. 


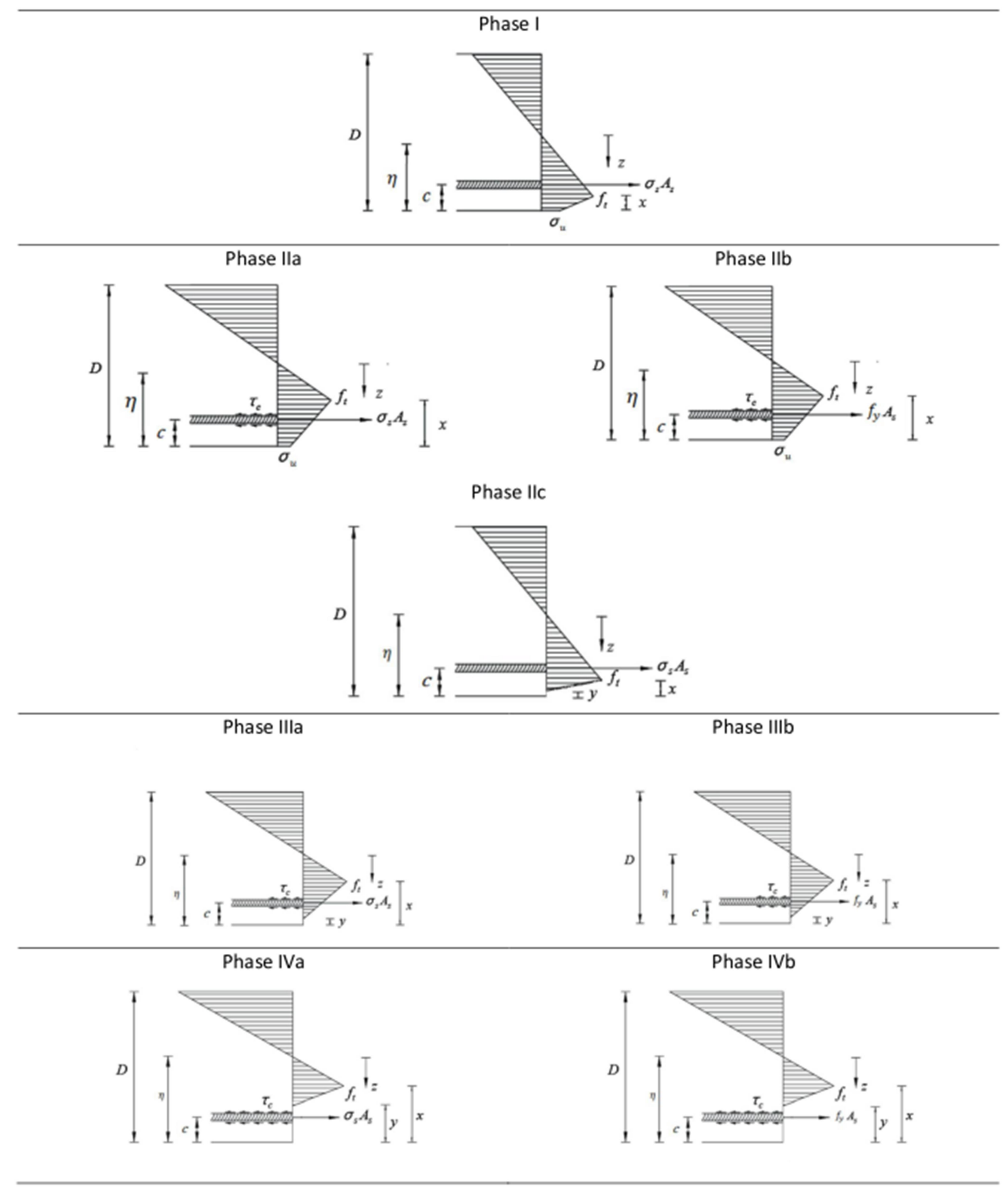

Figure 7: Stress distributions for the different phases in the analytical model. 
The different stress distributions characterizing the different phases are shown in figure 7. In the following $x$ denotes the crack length while $c$ denotes the cover layer. The concrete stress at the bottom of the beam is denoted by $\sigma_{u}$. Phase I is characterized by the crack being below the reinforcement and that the stresses at the cracked part of the cross section is described by the softening part of the stress strain relation. Perfect bond between the concrete and the steel is assumed. This stage is valid until the crack length $x$ is equal to the cover layer $c$ or until the concrete stress $\sigma_{u}$ at the bottom of the beam is equal to 0 . In phase IIa the crack has crossed the reinforcement and pullout of the reinforcement is starting. Furthermore the stresses in the cracked part of the cross section, is described by the softening of the stress strain relation. This phase is valid until the concrete stress $\sigma_{u}$ at the bottom of the beam is equal to 0 or yielding of the reinforcement is taking place. Phase IIb is similar to phase IIa except the steel stress here equals the yield stress of the reinforcement. Phase IIb is valid until the concrete stress $\sigma_{u}$ at the bottom of the beam is equal to 0 . At phase IIc the concrete stress $\sigma_{u}$ at the bottom of the beam is equal to 0 before the crack reaches the reinforcement. A zone with concrete stresses equal to 0 is developing. The length of this zone is denoted $y$. Perfect bond between concrete and reinforcement is assumed at this phase. Phase IIc is valid until the crack length $x$ is equal to the cover layer $c$. Phase IIIa is characterized by the crack having crossed the main reinforcement and the stresses in the cracked part of the cross section is partly described by the softening curve and a zone has developed where the concrete stresses are equal to 0 . However, the zone with concrete stresses equal to 0 have not yet crossed the reinforcement $(y<c)$. This stage is valid until the zone with concrete stresses equal to 0 reaches the reinforcement or yielding of the reinforcement occurs. Phase IIIb is similar to phase IIIa except the steel stress here equals the yield stress of the reinforcement. Phase IIIb is valid until the zone with concrete stresses equal to 0 reaches the reinforcement. At phase IVa the zone with concrete stresses equal to 0 has crossed the reinforcement. This phase is valid until the steel stress equals the yield stress of the reinforcement. Phase IVb is similar to phase IVa except yielding of the reinforcement is taking place. In figure 8 a flow chart is shown on how these different phases may follow each other in order to obtain the load deflection curve.

\subsection{Variation of model parameters}

In order to investigate the main trends of the analytical model, some of the important parameters of the model is varied. Throughout this paper, the reinforcement ratio is calculated as the steel area divided by the total cross section area. The load deflection curves for varying values of the reinforcement ratio are shown in figure 9. For increasing values of the reinforcement ratio, the yield load is increased proportionally with the reinforcement ratio. The first peak load is also increased when increasing the reinforcement ratio. For the cases shown in figure 9 a transition from being below the minimum reinforcement ratio to be meeting this requirement is taking place between $\rho=0.25 \%$ and $\rho=0.385 \%$. Load deflection curves for varying values of the friction stresses $\tau_{c}$ are shown in figure 10 . Whereas the yield load is practically independent of the value of the friction stresses, the first peak load is significantly increased by increasing the friction stress. After the unset of yielding, the load deflection curve is independent of the value of the friction stresses, however the deflection corresponding to the onset of yielding is highly influenced by the friction stress. For the cases with $\tau_{c}=2$ and $\tau_{c}=5$ shown in figure 10 , the first peak load is significantly below the yield load leading to larger values of the crack width and deflection before yielding takes place. Load deflection curves for varying values of the concrete tensile strength $f_{t}$ are shown in figure 11. 


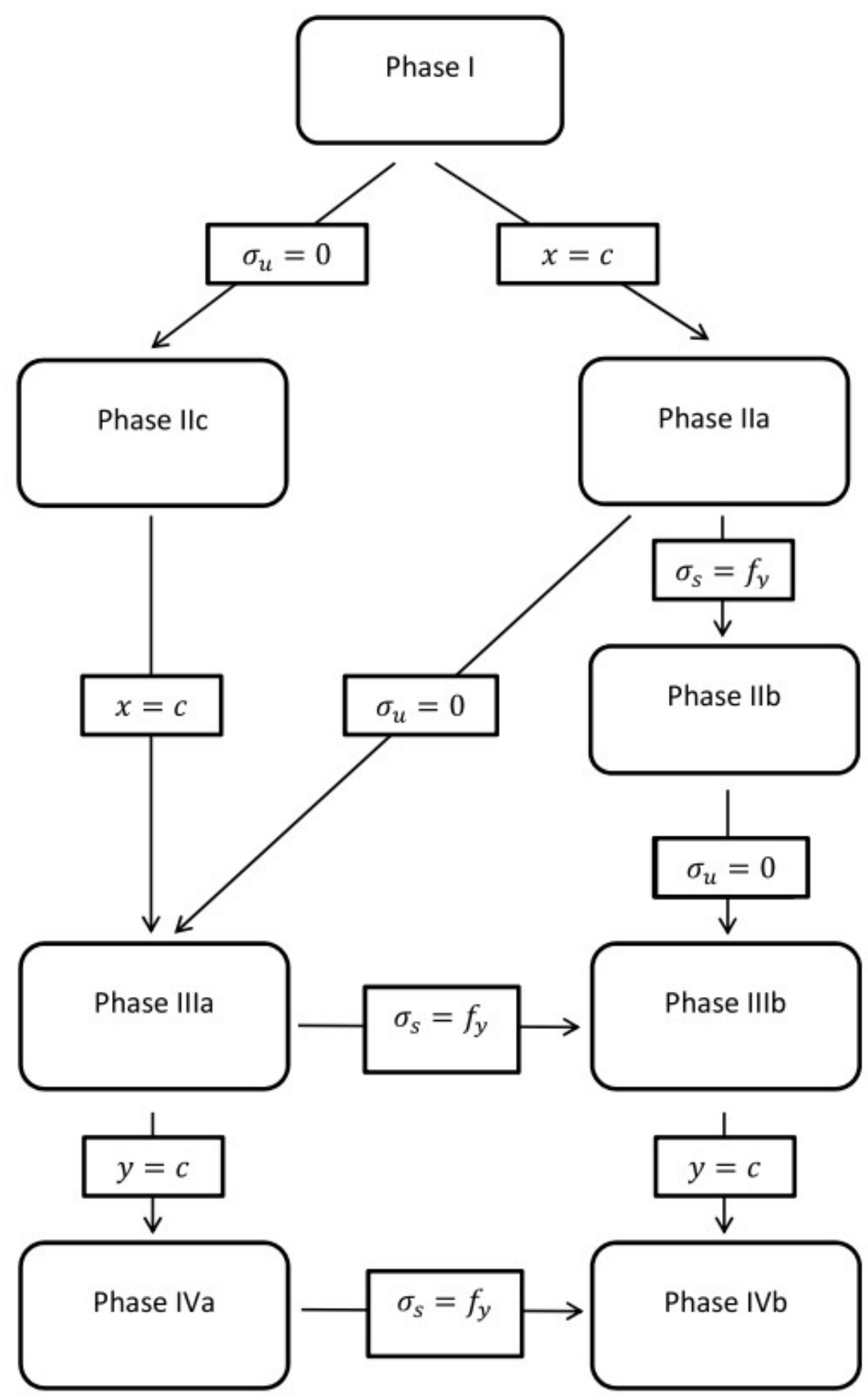

Figure 8: Flow chart showing how the different phases may follow each other in the analytical model. 


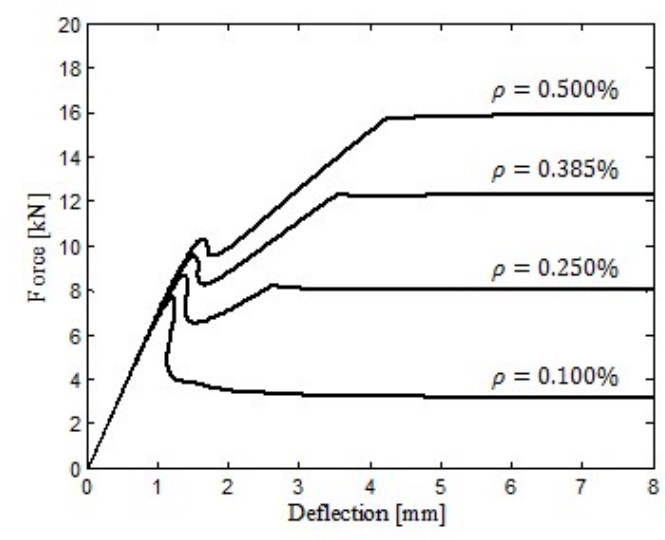

Figure 9: Variation of the reinforcement ratio.

The first peak load is highly influenced by the tensile strength while the yield load is unchanged. For the cases shown in figure $11 \mathrm{a}$ clear transition in the mechanical behavior of a concrete beam is observed. For the case with $f_{t}=2$ a monotonically increasing value of the load is observed until the onset of yielding whereas the case with $f_{t}=8$ is not fulfilling the minimum reinforcement requirements. The same transition in mechanical behavior of a concrete beam may be observed by changing the size of the beam. Dimensionless load deflection curves for different beam sizes are shown in figure 12. The dimensionless deflection is defined by the actual deflection divided by the deflection where the tensile strength is reached at the underside of the beam. The dimensionless load is defined by the actual load divided by the load where

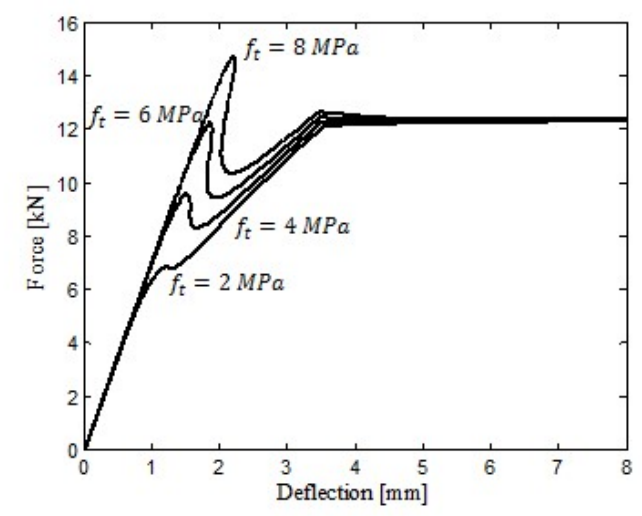

Figure 11: Variation of the tensile strength.

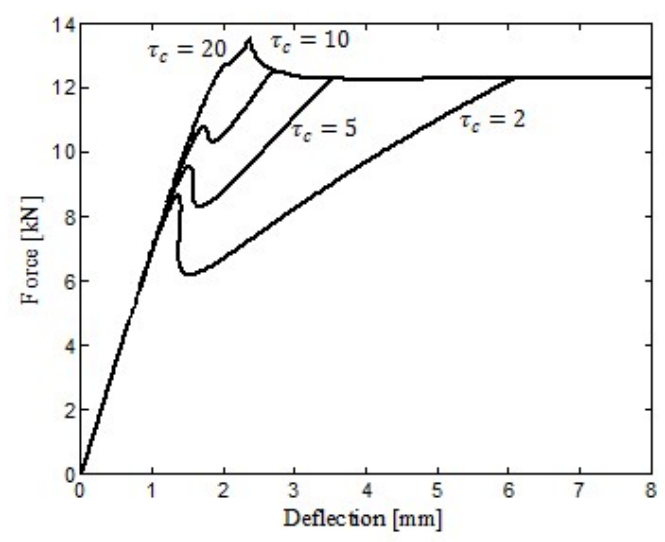

Figure 10: Variation of the friction stress $\tau_{c}$.

the tensile strength is reached at the underside of the beam. For the case with beam size $400 \times 200 \times 4800 \mathrm{~mm}$ the first peak load is significantly below the yield load whereas the case with beam size $50 \times 100 \times 600 \mathrm{~mm}$ is not fulfilling the minimum reinforcement requirements.

\section{COMPARISONS WITH TESTS}

In this section model solutions are compared with measured load deflection curves. The test results originate from a large research project on size effects and minimum reinforcement conducted at Aalborg University 1996-2000. A more detailed description of the tests can be found in [2122]. The test results shown in this section constitutes only a small part of the total number of test results available from this

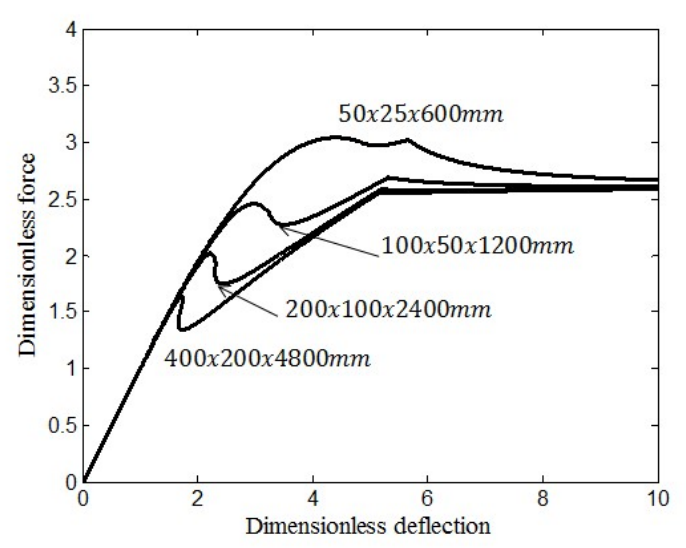

Figure 12: Variation of the beam size. 


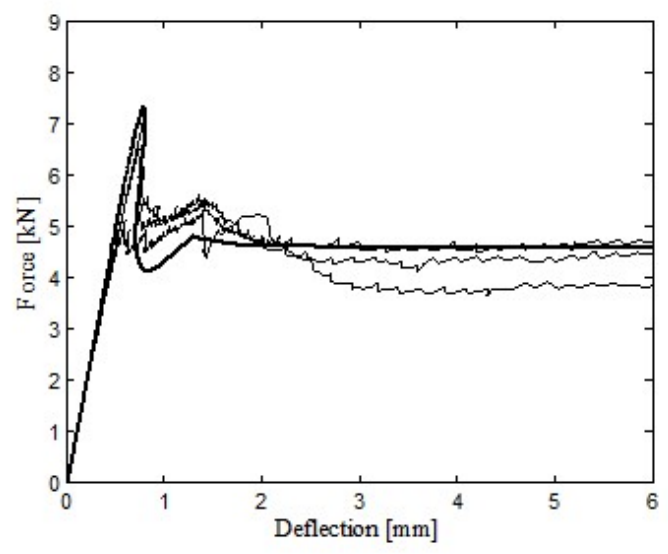

Figure 13: Comparison with test beam of HSC with $\rho=0.14$. Beam size: $100 \times 200 \times 2400 \mathrm{~mm}$.

research project. In this section model solutions are compared with test results from two different beam sizes with two different reinforcement ratios. For one beam size, results are shown for both normal strength concrete (NSC) and high strength concrete (HSC). For the other beam size results are only shown for the HSC beams. An overview of the reported test beam results is given in table 1 . Average values for the different mechanical properties measured for the test beams are found in [21] and stated in table 2. The shown model solutions are based on the values of the material parameters that are stated for each beam test in [21]. Test results for a HSC

Table 1: Test beams reported in this section.

\begin{tabular}{cccc}
\hline Beam size & Concrete & Rebar & $\rho[\%]$ \\
\hline & & & \\
& NSC & $1 \varnothing 6 \mathrm{~mm}$ & 0.14 \\
$\begin{array}{c}100 \times 200 \times 2400 \\
{[\mathrm{~mm}]}\end{array}$ & & $1 \varnothing 8 \mathrm{~mm}$ & 0.25 \\
& HSC & $1 \varnothing 6 \mathrm{~mm}$ & 0.14 \\
& & $1 \varnothing 8 \mathrm{~mm}$ & 0.25 \\
\hline $\begin{array}{c}\text { 200x400x4800 } \\
{[\mathrm{mm}]}\end{array}$ & HSC & $1 \varnothing 12 \mathrm{~mm}$ & 0.14 \\
& & $1 \varnothing 16 \mathrm{~mm}$ & 0.25 \\
\hline
\end{tabular}

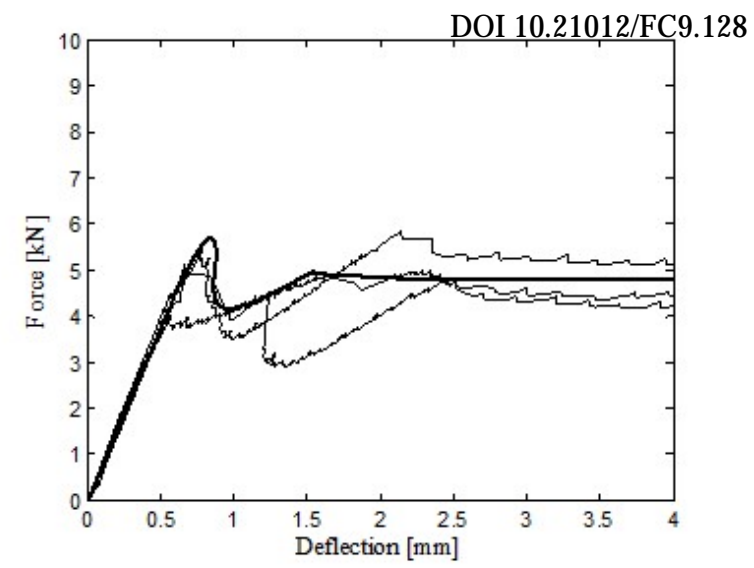

Figure 14: Comparison with test beam of NSC with $\rho=0.14$. Beam size: $100 \times 200 \times 2400 \mathrm{~mm}$.

beam of size $100 \times 200 \times 2400 \mathrm{~mm}$ with reinforcement ratio $\rho=0.14 \%$ is shown in figure 13 , together with a model solution. Both the test results and the model solution shows a significantly higher value of the first peak load compared to the yield load. Results for a similar beam cast of NSC are shown in figure 14. Both the tests and the model shows an almost equal value of the first peak load and the yield load, the first peak load being slightly higher than the yield load. Results for a $100 \times 200 \times 2400 \mathrm{~mm}$ HSC beam with $\rho=0.25 \%$ is shown in figure 15 . Both the tests and the model shows a significantly higher value for the yield load, compared with the first peak load. Comparing figure 13 and 15 it is clear that both the model and the tests shows a value for the minimum reinforcement ratio between $0.14 \%$ and $0.25 \%$.

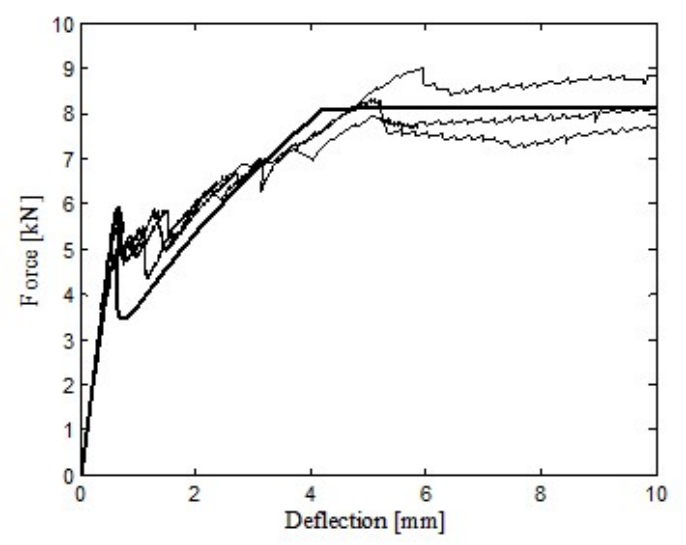

Figure 15: Comparison with test beam of HSC with $\rho=0.25$. Beam size: $100 \times 200 \times 2400 \mathrm{~mm}$. 


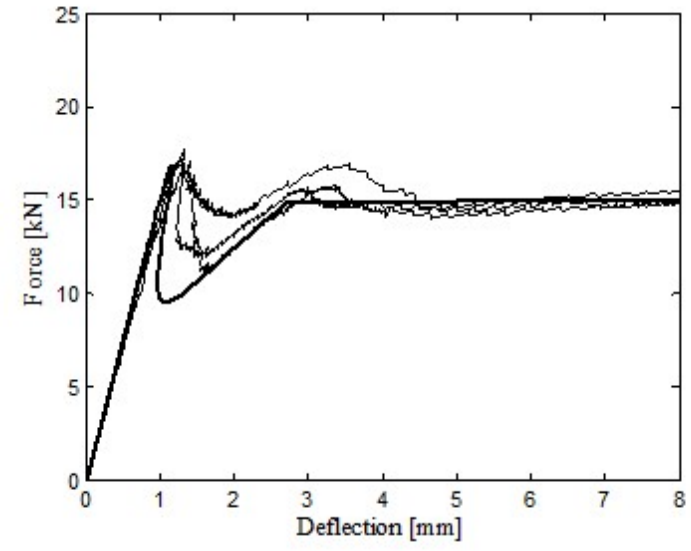

Figure 16: Comparison with test beam of HSC with $\rho=0.14$. Beam size: $200 \times 400 \times 4800 \mathrm{~mm}$.

Test results for a HSC beam of size 200x400x4800 $\mathrm{mm}$ with reinforcement ratio $\rho=0.14 \%$ is shown in figure 16 . Both the model and the tests show a slightly higher value for the first peak load than for the yield load. Test results and a model solution for a similar beam with reinforcement ratio $\rho=0.25 \%$ is shown in figure 17 . Also for this case it is clear that both the model and the test results show that the value for the minimum reinforcement ratio is between $0.14 \%$ and $0.25 \%$. Generally the model is able to predict the first peak load and the yield load in a manner that compares well with the test results. These comparisons have also shown that the model have a tendency to predict a more pronounced valley following the first

Table 2: Average values for the mechanical properties of the test beams

\begin{tabular}{ccc}
\hline & NSC & HSC \\
\hline $\begin{array}{c}\text { Compressive } \\
\text { strength }\end{array}$ & $64 \mathrm{MPa}$ & $99 \mathrm{MPa}$ \\
\hline $\begin{array}{c}\text { Splitting } \\
\text { strength }\end{array}$ & $4 \mathrm{MPa}$ & $6 \mathrm{MPa}$ \\
\hline $\begin{array}{c}\text { Modulus of } \\
\text { Elasticity }\end{array}$ & $40000 \mathrm{MPa}$ & $45000 \mathrm{MPa}$ \\
\hline $\begin{array}{c}\text { Fracture } \\
\text { energy }\end{array}$ & $126 \mathrm{~J} / \mathrm{m}^{2}$ & $118 \mathrm{~J} / \mathrm{m}^{2}$ \\
\hline \multicolumn{2}{c}{$\mathbf{R e i n f o r c e m e n t}^{2}$} \\
\hline $\begin{array}{c}\text { Yield } \\
\text { strength }\end{array}$ & $585 \mathrm{MPa}$ \\
\hline $\begin{array}{c}\text { Modulus of } \\
\text { elasticity }\end{array}$ & $201000 \mathrm{MPa}$ \\
\hline
\end{tabular}

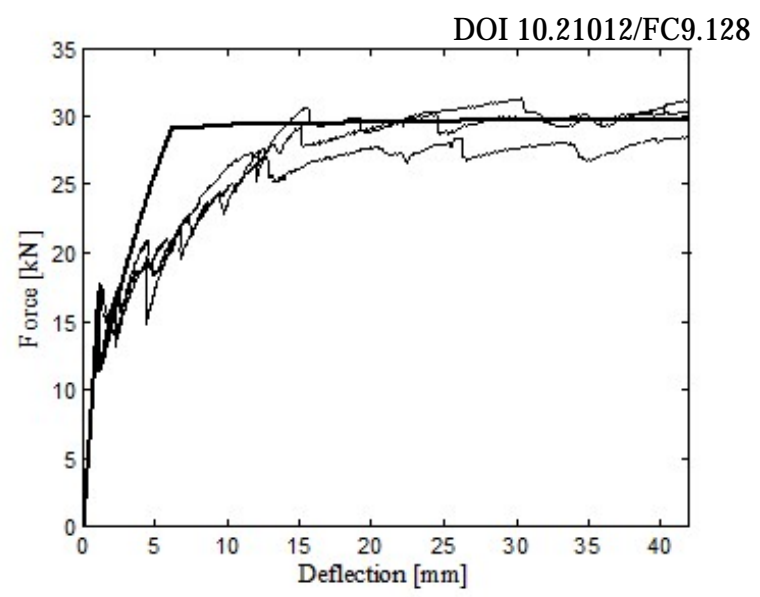

Figure 17: Comparison with test beam of HSC with $\rho=0.25$. Beam size: $200 \times 400 \times 4800 \mathrm{~mm}$.

peak load than shown in the measured load deflection curves. This tendency may be explained by the linear approximation of the stress crack width relation on which the model solution is based, figure 2. This linear approximation is based on the idea that the initial slope is the important parameter in modelling the first peak load. However this linear approximation leads to an amount of the fracture energy of the concrete that is not taken into account, leading to a deeper valley following the first peak load.

\section{CONCLUSIONS}

In this paper an analytical model for predicting the load deflection curve for lightly reinforced concrete beams has been established. The model shows that the key parameters in determining the first peak load associated with cracking are the beam size, the slope of the initial part of the stress crack width relation, the amount of reinforcement

Table 3: Input values used in the analytical model for the cases shown in figure 18

\begin{tabular}{ccc}
\hline & NSC & HSC \\
\hline$f_{t}$ & $3 \mathrm{MPa}$ & $6 \mathrm{MPa}$ \\
\hline$E_{c}$ & $20000 \mathrm{MPa}$ & $40000 \mathrm{MPa}$ \\
\hline$w_{1}$ & $0.1 \mathrm{~mm}$ & $0.1 \mathrm{~mm}$ \\
\hline$\tau_{c}$ & $5 \mathrm{MPa}$ & $5 \mathrm{MPa}$ \\
\hline \multicolumn{3}{c}{ Reinforcement } \\
\hline$f_{y}$ & \multicolumn{2}{c}{$500 \mathrm{MPa}$} \\
\hline$E_{s}$ & \multicolumn{2}{c}{$200000 \mathrm{MPa}$} \\
\hline
\end{tabular}




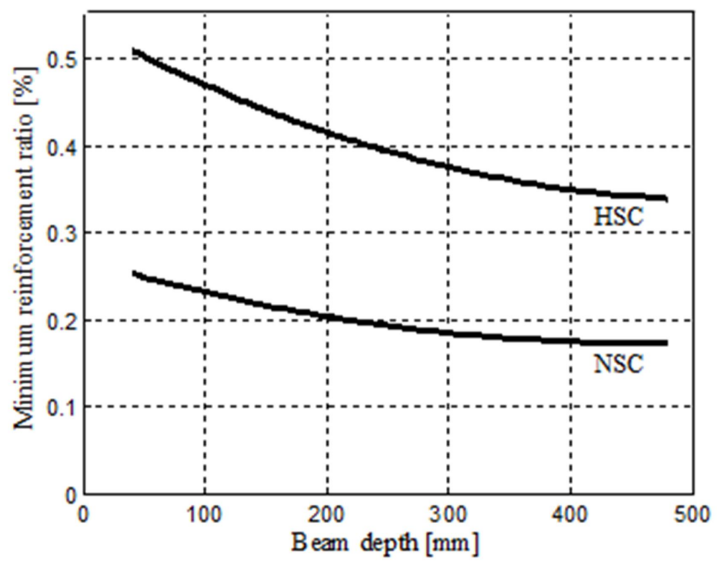

Figure 18: Model solutions for the minimum reinforcement ratio as function of beam depth.

and the bond properties between the reinforcement and the concrete. Generally the model solutions compares well with test results. An important feature of the model is the ability to predict the first peak load and the yield load within a degree of accuracy that makes the model suitable for evaluating the minimum reinforcement ratio. To make conclusions on the size effects on the minimum reinforcement ratio predicted by the model, one final case is considered. For a beam of size $0.5 D \times D \times 12 D$ the minimum reinforcement ratio has been determined with $D$ in the range of $40 \mathrm{~mm}-480 \mathrm{~mm}$. This has been done for values of the input parameters representing both a normal strength concrete and a high strength concrete. The values of these input parameters are shown in table 3. As seen from figure 18 a rather pronounced size effect on the minimum reinforcement ratio is predicted by the model.

\section{REFERENCES}

[1] Hillerborg, A., Modeer, M \& Petersson, P.E. (1976), Analysis of Crack Formation and Crack Growth in Concrete by Means of Fracture Mechanics and Finite Elements, Cement and Concrete Research, pp. 773-782.

[2] Bazant Z.P. \& Oh. B.H. (1983), Crack Band Theory for Fracture of Concrete, Materials and Structures, 161983 pp. 155177.
[3] Bosco C. \& Carpinteri AD(11 99.91) 1 1Eracture Mechanics Evaluation of Minimum Reinforcement in Concrete Structures. In Application of Fracture Mechanics to Concrete Structures. Ed. A Carpinteri, Elsevier Applied Science, Italy pp. 347377.

[4] Ulfkjær J.P., S. Krenk S. \& R. Brincker (1995), Analytical model for fictitious crack propagation in

concrete beams. Journal of Engineering Mechanics 1995:121(1) pp. 7-14.

[5] Planas J, G.V. Guinea \& M. Elices (1995), Rupture modulus and fracture properties of concrete. Fracture Mechanics of Concrete Structures. Ed. F. Wittmann, Germany.

[6] Hededahl O. \& Kroon I. (1991), Lightly Reinforced High-Strength Concrete. M.Sc. Thesis in Civil Engineering, AUC. [5]Brincker R. \& Dahl H. (1989), Fictitious Crack Model of Concrete Fracture, Magazine of Concrete Research 41, No. 147 pp 79-86.

[7] Olesen J.F. (2001), Cracks in reinforced FRC beams subject to bending and axial load. Fourth International Conference on Fracture Mechanics of Concrete and Concrete Structures, Cachan.

[8] ACI318M-11. Building Code

Requirements for Structural Concrete and Commentary. 2011.

[9] EC2:BS EN 1992. Design of concrete structures. General rules and rules for buildings. 2004.

[10] Carpinteri A, Cadamuro E, Corrado M. Minimum flexural reinforcement in rectangular and T-section concrete beams. Struct Concr. 2014;15(3):361-72.

[11] Gerstle WH, Dey PP, Prasad NN V, Rahulkumar P, Xie M. Crack growth in flexural members. A fracture mechanics approach. ACI Struct J. 1992;89(89):61725.

[12] Rao GA, Vijayanand I. Studies on ductility and evaluation of minimum flexural reinforcement in RC beams. Mater Struct. 2008;41:759-71.

[13] Rao GA, Aravind J, Eligehausen R. Evaluation of minimum flexural 
reinforcement in RC beams. J Struct Eng. 2007;34:277-83.

[14] Ruiz G, Elices M, Planas J. Size effeects and bond-slip dependency of lightly reinforced concrete beams. Minimum Reinforcement in Concrete Members ESIS. Elsevier; 1999.

[15] Bosco C, Carpinteri A, Debernardi PG. Minimum reinforcement in high- strength concrete. J Struct Eng. 1990;116(2):42737.

[16] Bazant Z., Kim J. K. Size effect in shear failure of longitudinally reinforced beams. ACI J. 1984;81:456-68.

[17] Ozbolt J, Bruckner M. Minimum Reinforcement Requiremnts for RC Beams. Minimum Reinforcement in Concrete Members -ESIS. Elsevier; 1999

[18]Elices M., Guinea G.V. \& Planas J. (1994). Prediction of Size-effect based on Cohesive Crack Model. In Size-scale effects In the failure mechanisms of materials and structures. Ed. A. Carpinteri. Symposium on Size-scale effects in the failure mechanisms of materials and structures. Torino.

[19]Jensen E.A. (2002). Investigation of Cracking Process and Aggregate Interlocking Properties of JPCP Cracks. Ph.D.-thesis at the University of Michigan.

[20] Brincker R., Simonsen J. \& Hansen W. (1997), Some aspects of formation of cracks in FRC with main reinforcement. In Nordic Concrete Research. Publication no. 201997.

[21] Henriksen M.S. (2004), Deformation capacity and cracking of reinforced concrete beams. Ph.D. Thesis. Aalborg University, Denmark.

[22] Brincker R., et. Al. (1997), Size effects on the bending behavior of reinforced concrete beams. In Minimum Reinforcement in Concrete Members: ESIS Publication 24. ed. / Alberto Carpinteri. Pergamon Press, 1999. p. 127137. 